in the syringe and injected into $3.00 \mathrm{~mL}$ of an aqueous solution containing $0.0091 \mathrm{~N} \mathrm{HCl}$ and $0.017 \mathrm{M} \mathrm{KCl}$. The temperature of the solution was maintained at $60^{\circ} \mathrm{C}$ by using a water bath, and the procedure was performed inside an enclosure containing a nitrogen atmosphere. Another aqueous solution was prepared which contained $0.02 \mathrm{M}$ Tris in the free base form, and $2 \times 10^{-5}$ $M 1$. After equal volumes of these two solutions were mixed in the stopped-flow spectrophotometer, the final $\mathrm{pH}$ was measured as 7.50. After correction for a $0.025-\mathrm{mL}$ holdup in the injection syringe, the final concentration of 2 was calculated to be $5.02 \times$ $10^{-4} \mathrm{M}$ and that of 3 to be $5.00 \times 10^{-4} \mathrm{M}$. In all experiments, the ionic strength of the mixed solution was calculated to be $0.01 \pm$ 0.003 , disregarding the contribution of the surfactant to the ionic strength.

Kinetic Studies. Reactions were monitored with a Durrum Model D-130 stopped-flow spectrophotometer equipped with a Beckmann Model DU-2 monochromater and a Tektronix Model 5103N/D15 storage oscilloscope. The oscilloscope readout was photographed by using a Polaroid camera. A constant-temperature circulating bath maintained the temperature at $25 \pm 0.2$ ${ }^{\circ} \mathrm{C}$. The appearance of the Ells ${ }^{-}$product was followed at 445 $\mathrm{nm} .{ }^{13 \mathrm{~b}}$ All reactions were monitored with two oscilloscope time bases, one appropriate to the faster reactions and one appropriate to the slower reactions. Rate constants were calculated from the appropriate traces. First-order kinetic behavior was observed for the fastest reaction, with correlation coefficients greater than 0.999 for computer-generated correlations of $\log \left(A_{1}{ }^{\infty}-A^{t}\right)$ with time. The fastest reaction was rapid enough so that product oxidation could be ignored.

The rate of the second reaction in Scheme I was in all cases comparable to the rate of product oxidation. The relative rate constants for the second reaction were therefore calculated from the maximum product concentrations observed. The relative maximum concentration from the second step, $\beta_{\max }$, was obtained by subtracting from the maximum observed concentration that amount of product that was due to the first step $\left(1 \times 10^{-5} \mathrm{M}\right)$ and then dividing the result by the theoretical total product yield from the second step (also $1 \times 10^{-5} \mathrm{M}$ ). If $k_{\psi 2}$ is the pseudo-first-order rate constant for the second step in Scheme I and $k_{0 x}$ is the pseudo-first-order rate constant for product oxidation, then $\beta_{\max }$ can be approximated by $\left(k_{0 x} / k_{\psi 2}\right)$ raised to the power $k_{0 x} /\left(k_{\psi 2}-\right.$ $\left.k_{\mathrm{ox}}\right)^{22}$ The ratio between $k_{\psi 2}$ and $k_{\mathrm{ox}}$ was then calculated for $\beta_{\max }$ in each case. On the assumption that $k_{0 x}$ was the same in each case, the "ratio of ratios" thus gave the relative rate constants for the second step at different thiol concentrations. ${ }^{23}$

The estimate of $k_{2}$ was obtained from measurement of the time at which $\beta_{\max }$ was observed, $\tau_{\max }$ in the experiment with $0.001 \mathrm{M}$ 2. By use of the above rate constants, $\tau_{\max }$ can be approximated by $\left(1 /\left(k_{o x}-k_{\psi 2}\right)\right) \ln \left(k_{o x} / k_{\psi 2}\right){ }^{22}$ The nature of the absorption vs. time reaction trace was such that a precise $\tau_{\max }$ value was not obtained; nevertheless $\tau_{\max }$ lay between 10 and $100 \mathrm{~s}$. Using these two boundary $\tau_{\max }$ values and the relation $k_{\text {ox }}=0.138 k_{\psi 2}$ (from the $\beta_{\max }$ value), we calculated that $0.0032 \mathrm{~s}^{-1}<k_{\psi 2}<0.032 \mathrm{~s}^{-1}$; we thus estimate that $k_{2}<32 \mathrm{~L} \mathrm{~mol}^{-1} \mathrm{~s}^{-1}$.

The occurrence of the oxidation reaction, which forces us to resort to the foregoing analysis, cannot be easily prevented. The vesicles were prepared in a nitrogen atmosphere, but oxygen is apparently introduced during the transfer of the solutions to the stopped-flow spectrophotometer. We suspect that only be enclosing that instrument in a nitrogen atmosphere, and thus performing the entire experiment under an inert atmosphere, could we completely eliminate the complication of product oxidation.

Acknowledgment. I thank Professor Robert A. Moss for helpful discussions and Professor Jean-Marie Lehn for assistance in preparing this paper. Financial support from

(22) Moore, J. W.; Pearson, R. G. "Kinetics and Mechanism", 3rd ed. Wiley: New York, 1981; p $290 \mathrm{ff}$

(23) It must be noted that this is a crude calculation; the relations used are exactly true only for two consecutive first-order reactions. The system we observed involved two parallel pseudo-first-order reactions, followed by a third, consecutive pseudo-first-order reaction. There is no simple kinetic solution which can analyze completely such a system. Therefore, the initial reaction has been ignored, because it is much more rapid than the two reactions which follow. the National Science Foundation is also gratefully acknowledged.

Registry No. 1, 69-78-3; 2, 79246-00-7; 3, 70755-47-4; (n$\left.\mathrm{C}_{16} \mathrm{H}_{33}\right)_{2} \mathrm{~N}^{+}\left(\mathrm{CH}_{3}\right) \mathrm{CH}_{2} \mathrm{CH}_{2} \mathrm{SSEll}, 85908-82-3$.

\section{Diels-Alder Reactions of 2-Alkynoyl Chlorides with Cyclopentadiene: A Reinvestigation}

\author{
Englbert Bäuml and Herbert Mayr* \\ Institut für Organische Chemie der \\ Friedrich-Alexander-Universität Erlangen-Nürnberg, \\ D-8520 Erlangen, Federal Republic of Germany
}

Received November 16, 1982

Diels-Alder reactions of cyclopentadiene represent a simple access to the bicyclo[2.2.1] skeleton. ${ }^{1 \mathrm{a}}$ While electron-deficient alkenes react readily with cyclopentadiene, ${ }^{1 \mathrm{~b}, \mathrm{c}}$ cycloadditions to triple bonds appear to be problematic.

While alkenoyl chlorides are among the most reactive dienophiles, ${ }^{\mathrm{lb}, \mathrm{c}}$ phenylpropynoyl chloride has been reported "not to undergo appreciable reaction with cyclopentadiene at room temperature even after $24 \mathrm{~h}{ }^{2}$ Therefore, Baum and Viehe used a route via acetylenic iminium salts for synthesizing compounds of type $4 .^{3}$ In earlier papers, however, Diels-Alder reactions of $1 \mathrm{a}$ with cyclopentadiene have been reported. ${ }^{4,5}$ Forty-one percent of cycloadduct was obtained when a solution of $1 \mathrm{a}$ and 2 in toluene was heated at reflux for $48 \mathrm{~h}^{4}$ Other workers describe a spontaneous reaction of $1 \mathrm{a}$ with 2 at room temperature in the presence of a "few crystals of picric acid". The inconsistency of these reports prompted us to reexamine the reactions of alkynoyl chlorides with cyclopentadiene.

When $1 \mathrm{a}$ and 2 were mixed at $0^{\circ} \mathrm{C}$, warmed up to room temperature, and poured into a suspension of sodium bicarbonate in methanol, $84 \%$ of ester $4 \mathrm{a}$ was obtained. Combining these cycloaddends without external cooling resulted in a rapid exothermic cycloaddition reaction accompanied by partial polymerization of cyclopentadiene. Alkynoyl chlorides $\mathbf{1 b}$ and $1 \mathrm{c}$ reacted with cyclopentadiene at room temperature to give good yields of norbornadienes $\mathbf{4 b}$ and $4 c$, respectively. Because of the mild reaction

$$
\begin{array}{ll}
1 \mathrm{a}, \mathrm{R}=\mathrm{Ph} \\
\mathrm{b}, \mathrm{R}=\mathrm{CH}_{3} \\
\mathrm{c}, \mathrm{R}=\mathrm{C}\left(\mathrm{CH}_{3}\right)_{3}
\end{array}
$$

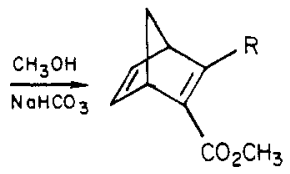

conditions employed for these cycloadditions ${ }^{6}$ and the versatile reactivity of acid chlorides 3 , we consider the title reaction as the method of choice for the synthesis of any

(1) (a) Sauer, J. Angew. Chem., Int. Ed. Engl. 1966, 5, 211. (b) Saver J.; Wiest, H.; Mielert, A. Z. Naturforsch., B: Anorg. Chem., Org. Chem. Biochem., Biophys. Biol. 1962, 17, 203. (c) Sauer, J. Angew. Chem., Int. Ed. Engl. 1967, 6, 16.

(2) Glass, R. S.; Smith, D. L. J. Org. Chem. 1974, 39, 3712

(3) Baum, J. S.; Viehe, H. G. J. Org. Chem. 1976, 41, 183.

(4) Cristol, S. J.; LaLonde, R. T. J. Am. Chem. Soc. 1959, 81, 5417.

(5) Poos, G. I.; Kleis, J.; Wittekind, R. R.; Rosenau, J. D. J. Org. Chem. $1961,26,4898$.

(6) Diels-Alder reaction of 2-butynoic acid with cyclopentadiene is carried out at $185^{\circ} \mathrm{C}$ : Simmross, F.-M.; Weyerstahl, P. Liebigs Ann. Chem. 1981, 1089. 
norbornadiene-2-carboxylic acid derivatives. Since even the sterically hindered tertiary butyl compound $1 \mathrm{c}$ reacts readily at room temperature, this reaction should be of general applicability.

\section{Experimental Section}

General Procedures. Infrared spectra were recorded on a Beckman Acculab 1 IR spectrophotometer. ${ }^{1} \mathrm{H}$ NMR spectra were taken in carbon tetrachloride on a JEOL JNM-C-60-HL spectrometer, and mass spectra were recorded on a Varian MAT CH 4 spectrometer.

Methyl 3-Phenylbicyclo[2.2.1]hepta-2,5-diene-2carboxylate (4a). Cyclopentadiene $(2.70 \mathrm{~g}, 40.9 \mathrm{mmol})$ was added to precooled $\left(0^{\circ} \mathrm{C}\right)$ phenylpropynoyl chloride $\left(1 \mathrm{a} ; ;^{7} 6.00 \mathrm{~g}, 36.5\right.$ mmol) in a nitrogen atmosphere and the mixture was allowed to warm to $20^{\circ} \mathrm{C}$ within $4 \mathrm{~h}$. After $10 \mathrm{~h}$, more cyclopentadiene $(2.70$ $\mathrm{g}, 40.9 \mathrm{mmol}$ ) was added. After the mixture was stirred for 24 h, la was consumed completely (monitoring by NMR) and the mixture was added slowly to a suspension of $\mathrm{NaHCO}_{3}(3.5 \mathrm{~g})$ in $50 \mathrm{~mL}$ of methanol. After $1 \mathrm{~h}$, the mixture was filtered and the solvent evaporated. The residue was dissolved in $20 \mathrm{~mL}$ of ether and filtered, the ether evaporated, and the residue distilled: 6.93 $\mathrm{g}(84 \%)$ of $4 \mathrm{a}$; bp $109-110^{\circ} \mathrm{C}(0.2 \mathrm{mmHg})$ [lit. ${ }^{4}$ bp $111-116^{\circ} \mathrm{C}$ $(0.6 \mathrm{mmHg})]$; IR (neat) $3050,2980,2940,2870,1705,1605,1590$, $1485,1425,1330,1290,1230,1185,1145,1095,1080,1070,755$, $715,690 \mathrm{~cm}^{-1} ;{ }^{1} \mathrm{H} \mathrm{NMR}\left(\mathrm{CCl}_{4}\right) \delta 2.03,2.23$ (br AB system, $J=$ $7 \mathrm{~Hz}, 2 \mathrm{H}), 3.60$ (s, $1 \mathrm{H}), 3.82$ (br s, $1 \mathrm{H}), 4.03$ (br s, $1 \mathrm{H}), 6.94$ (br s, $2 \mathrm{H}$ ), 7.1-7.7 (m, $5 \mathrm{H})$; mass spectrum $(70 \mathrm{eV}), \mathrm{m} / \mathrm{e}$ (relative intensity) $226\left(100, \mathrm{M}^{+}\right), 195(24), 167(63), 166(21), 165$ (39), 161 (69), 152 (15), 129 (47).

Anal. Calcd. for $\mathrm{C}_{15} \mathrm{H}_{14} \mathrm{O}_{2}: \mathrm{C}, 79.62 ; \mathrm{H}, 6.24$. Found: $\mathrm{C}, 79.50$ H, 5.96 .

Methyl 3-Methylbicyclo[2.2.1]hepta-2,5-diene-2carboxylate (4b). 2-Butynoyl chloride (1b; from 2-butynoic acid ${ }^{8}$ and $\left.\mathrm{SOCl}_{2}, 94.00 \mathrm{~g}, 39.0 \mathrm{mmol}\right)$ and cyclopentadiene $(2.70 \mathrm{~g}, 40.9$ $\mathrm{mmol})$ were combined at room temperature $\left(\mathrm{N}_{2}\right.$ atmosphere). After $48 \mathrm{~h}$ at ambient temperature more cyclopentadiene $(2.70$ $\mathrm{g}, 40.9 \mathrm{mmol}$ ) was added, and the mixture was left for another $48 \mathrm{~h}$ and worked up as above. The crude material was purified by filtration over silica gel. After elution of dicyclopentadiene with petroleum ether, $4 \mathrm{~b}$ was eluted with ether, the ether evaporated, and the residue distilled: $5.0 \mathrm{~g}(78 \%)$ of $4 \mathrm{~b} ; \mathrm{bp} 67-70^{\circ} \mathrm{C}$ $(4 \mathrm{mmHg})$ [lit. $\left.{ }^{6} \mathrm{bp} 85-90^{\circ} \mathrm{C}(15 \mathrm{mmHg})\right]$. For spectral data, see ref. 6 .

Methyl 3-tert-Butylbicyclo[2.2.1]hepta-2,5-diene-2carboxylate (4c). 4,4-Dimethyl-2-pentynoyl chloride (1c; from 4,4-dimethyl-2-pentynoic acid ${ }^{10}$ and $\mathrm{SOCl}_{2},{ }^{9} 9.00 \mathrm{~g}, 62.2 \mathrm{mmol}$ ) and cyclopentadiene $(5.00 \mathrm{~g}, 75.6 \mathrm{mmol})$ were combined at $20^{\circ} \mathrm{C}$ $\left(\mathrm{N}_{2}\right.$ atmosphere). After $30 \mathrm{~h}$ more cyclopentadiene $(4.10 \mathrm{~g}, 62.0$ mmol) was added, and the mixture was stirred for 5 days at room temperature and worked up as described for $4 \mathrm{a}: 10.5 \mathrm{~g}(82 \%)$ of $4 \mathrm{c} ; \mathrm{bp} 62-64.5^{\circ} \mathrm{C}(1 \mathrm{mmHg})$; IR (neat) $3070,2950,2870,1720$, $1600,1560,1480,1460,1435,1365,1300,1235,1195,1160,1090$, $1050,725 \mathrm{~cm}^{-1} ;{ }^{1} \mathrm{H}$ NMR $\left(\mathrm{CCl}_{4}\right) \delta 1.16(\mathrm{~s}, 9 \mathrm{H}), 1.88(\mathrm{~m}, 2 \mathrm{H}), 3.67$ (s and $\mathrm{m}, 5 \mathrm{H}), 6.82(\mathrm{~m}, 2 \mathrm{H})$; mass spectrum $(70 \mathrm{eV}), \mathrm{m} / e$ (relative intensity) $206\left(58, \mathrm{M}^{+}\right), 191(21), 175(22), 174(40), 159(24), 147$ (80), 141 (51), $131(100)$.

Anal. Calcd for $\mathrm{C}_{13} \mathrm{H}_{18} \mathrm{O}_{2}: \mathrm{C}, 75.69 ; \mathrm{H}, 8.80$. Found: C, 76.00; $\mathrm{H}, 9.05$.

Acknowledgment. We thank the Deutschen Forschungsgemeinschaft and the Fonds der Chemischen Industrie for support of this work.

Registry No. 1a, 7299-58-3; 1b, 39753-54-3; 1c, 52324-03-5; 4a, 24161-43-1; 4b, 85894-25-3; 4c, 85894-26-4; cyclopentadiene, 542-92-7.

(7) Bergmann, F.; Haskelberg, L. J. Am. Chem. Soc. 1941, 63, 2243.

(8) Simmross, F.-M.; Weyerstahl, P. Synthesis 1981, 72.

(9) General procedure: "Organikum", 7th ed.; VEB Deutscher Verlag der Wissenschaften: Berlin, 1967; p 409 .

(10) Moreu, C.; Delange, R. Bull. Soc. Chim. 1903, 29, 648.
Sulfinic Acids and Related Compounds. 14. Derivatives of 3-Sulfinopropanoic Acid ${ }^{1,2}$

\section{J. Mark Hoch and Lamar Field*}

Department of Chemistry, Vanderbilt University, Nashville, Tennessee 37235

Received November 16, 1982

Sulfinate salts containing di- or trisulfide linkages have shown promise as antiradiation drugs. ${ }^{3}$ An attractive alternative to long sequential syntheses of such structures would be convergent syntheses in which separately synthesized sulfinic acid derivatives and di- or trisulfides become connected by a carboxylate ester linkage involving $\mathrm{CO}_{2} \mathrm{H}$ on one of the synthons and $\mathrm{OH}$ on the other. For such purposes, 3-sulfinopropanoic acid (1), as its sulfinate salt (2) or ester (3), is an attractive synthon both per se and as a model. This paper reports studies of several compounds related to 1 : the salt 2 , the diacid dichloride 4 , the diester 5 , the thiolsulfonate 6 , and various related compounds.

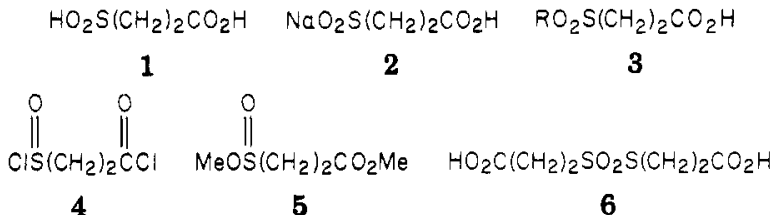

A reported method for oxidizing thiols to sulfinic acids, in which $m$-chlorobenzoic acid precipitates, ${ }^{6}$ was unsatisfactory with 3-mercaptopropanoic acid (7) because 1 coprecipitated. However, when an alkaline solution of the products was adjusted to $\mathrm{pH} 3$, the acid $1\left(\mathrm{p} K_{\mathrm{a}}\right.$ probably of $\sim 2$ for $\left.\mathrm{SO}_{2} \mathrm{H}\right)^{7}$ remained in solution as its salt, while $m$-chlorobenzoic acid could be extracted $\left(\mathrm{p} K_{\mathrm{s}}=3.8^{8}\right.$ sparingly soluble). The spectra of 2 obtained by evaporating the aqueous phase met expectation and showed a negligible amount of $m$-chlorobenzoic acid. Titration for sulfinic acid content by the method of Marvel and Johnson, by using nitrous acid, ${ }^{9}$ indicated a content in the salt 2 of $\sim 94 \%$ of sulfinate (with allowance for $\mathrm{NaCl}$, which could not readily be separated and usually would be inconsequential); this titration is selective for sulfinic acids in the presence of sulfonic or carboxylic acids and related materials. ${ }^{9 \mathrm{~b}}$ The identity of the 2 was confirmed by conversion to a bis(benzylthiuronium) salt. Efforts to condense the carboxy salt 2 with bis(2-hydroxyethyl) disulfide have been unpromising so far because of solubility problems, ${ }^{2}$ however, and we therefore turned to a study of the diacid dichloride 4 .

Douglass and Farah prepared 4 by chlorinating the mercapto acid $7,{ }^{10}$ and others also have encountered no

(1) For paper 13, see Eswarakrishnan, V.; Field, L. J. Org. Chem. 1981, $46,4182-4187$.

(2) Abstracted from part of the M.S. Thesis of J. Mark Hoch, Vanderbilt University, Nashville, TN, Dec 1982, which can be consulted for further details.

(3) For leading citations, see ref 1,4 and 5

(4) Klayman, D. L.; Copeland, E. S. In "Drug Design"; Ariëns, E. J., Ed.; Academic Press: New York, 1975; Vol. 6, pp 81-142.

(5) Sweeney, T. R. "A Survey of Compounds from the Antiradiation Drug Development Program of the U.S. Army Medical Research and Development Command"; Walter Reed Army Institute of Research: Washington, DC, 1979 ; see especially pp $5,672,688,689,769$, and 770 . (6) Filby, W. G.; Günther, K.; Penzhorn, R. D. J. Org. Chem. 1973, 38, 4070-4071.

(7) Cf. Oae, S.; Kunieda, N. In “Organic Chemistry of Sulfur”; Oae, S. Ed.; Plenum Press: New York, 1977; p 612.

(8) Davis, M. M. "Acid-Base Behavior in Aprotic Organic Solvents" U.S. Government Printing Office: Washington, DC, 1968; p 33.

(9) (a) Marvel, C. S.; Johnson, R. S. J. Org, Chem. 1948, 13, 822-829. (b) Cf. also Kice, J. L.; Bowers, K. W. J. Am. Chem. Soc. 1962, 84, 605-610. 